\title{
Re-Designing GB's Electricity Market Design: A Conceptual Framework Which Recognises the Value of Distributed Energy Resources
}

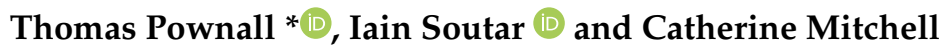 \\ Energy Policy Group, University of Exeter, Penryn TR10 9FE, UK; I.Soutar@exeter.ac.uk (I.S.); \\ Catherine.Mitchell@exeter.ac.uk (C.M.) \\ * Correspondence: t.pownall@exeter.ac.uk
}

check for

updates

Citation: Pownall, T.; Soutar, I.; Mitchell, C. Re-Designing GB's Electricity Market Design: A Conceptual Framework Which Recognises the Value of Distributed Energy Resources. Energies 2021, 14, 1124. https://doi.org/10.3390/ en14041124

Academic Editors:

Malcolm McCulloch and

Rebecca Ford

Received: 30 December 2020

Accepted: 17 February 2021

Published: 20 February 2021

Publisher's Note: MDPI stays neutral with regard to jurisdictional claims in published maps and institutional affiliations.

Copyright: (c) 2021 by the authors. Licensee MDPI, Basel, Switzerland. This article is an open access article distributed under the terms and conditions of the Creative Commons Attribution (CC BY) license (https:/ / creativecommons.org/licenses/by/ $4.0 /)$.

\begin{abstract}
The design of electricity markets determines the technologies, services and modes of operation that can access value, consequently shaping current and future electricity landscapes. This paper highlights that the efficacy of Great Britain's electricity market design in facilitating net zero is inadequate and must be reconfigured. The rules of the current electricity market design are remnants of an electricity sector dominated by large-scale, centralised, fossil fuel technologies. Therefore, routes to market for the provision of necessary services to support net zero, not least flexibility, are largely inaccessible for distributed energy resources and, despite their benefits to the system, are thus undervalued. Based upon a review and consolidation of 30 proposed electricity market designs from liberalised electricity sectors, this paper proposes a new electricity market design for Great Britain. This design is presented alongside a new institutional framework to aid in the efficient operation of the market. Specifically, this paper proposes a new local balancing and coordinating market located at each grid supply point (the transmission and distribution interface). This is realised through the implementation of a distributed locational marginal pricing structure which is governed by the evolution of the current distributed network operator, known as the distributed service provider (DSP). The DSP also operates a local balancing and ancillary market for their geographical area. The wholesale market is reconfigured to coordinate with these new local markets and to harmonise the actors across the distribution and transmission network.
\end{abstract}

Keywords: distribution gap; smart energy system; COVID-19; distributed locational marginal price; decentralised electricity system

\section{Introduction}

Since the turn of the century, the electricity sectors of many industrialised nations, including Great Britain (GB), have undergone fundamental political and technological paradigm shifts. This is realised through the combination of policy directives in response to anthropogenic climate change and the subsequent technological innovations leading to the displacement of conventional generating units [1-4].

The hierarchy of the electricity sector has shifted from a predominantly centralised, topdown and linear model to one where centralised and distributed technologies coexist [5-8]. In parallel to the deployment of distributed energy resources (DER) such as small-scale solar and onshore wind, the development of the Internet of Things (IoT) is unlocking flexible capacity from the once passive demand side $[7,9,10]$, permitting trades of electricity and ancillary services at the local level $[7,11]$.

As well as requiring new modes of electricity system operation, this also enhances the value of decentralised technologies, which-in a departure from traditional load-following principles-can increasingly receive financial compensation for the services that they provide to the system. 
To access the opportunities arising from an increasingly decentralised electricity system, such as unlocking and utilising local flexibility to solve grid issues [12,13], using this flexibility to defer costly network reinforcement [14-18] and reducing balancing costs by locating generation close to demand [9,19-21], appropriate institutional governance is required [22-24]. Governance for net zero necessitates multiple changes to institutional frameworks, from placing new duties on current regulators and devolving energy governance to local levels, to the reconfiguration of the electricity market design [22,24-26]. This paper focuses on the latter. Market design influences electricity transition pathways by determining which technologies and services can provide firms with revenue streams. The rules which govern participation within electricity markets, the market design, are important as they determine market winners and losers by defining the value of services (e.g., of power and flexibility) and the technologies which could provide them [24,27-31].

Those technologies deemed eligible to participate within a specific market and extract value from the provision of a service, whether generation asset or demand-side assets, will be seen as favourable investments compared to those with no viable route to the market even if that technology offers value to the overall system in the context of net zero [32-34]. To date, the electricity system has relied upon large-scale, centralised forms of generating assets such as coal and combined cycle gas turbines plants. As these generating assets were prominent at the time of privatisation and the subsequent New Electricity Trading Arrangements (NETA), the electricity market design was based upon their characteristics [35,36].

The legacy of a centralised market design has resulted in a 'distribution gap', a void in the institutional framework at the distribution level, as evidenced by the lack of routes to market for embedded technologies, which are often serviced in the retail market instead $[33,37,38]$. As it stands, the economics of electricity generation are skewed towards centralised technologies, and electricity markets therefore need to be re-designed to both unlock investment in DER as well as the adoption of associated business models [11,39].

This paper provides a conceptual framework for a new electricity market design which advocates the introduction of a balancing and coordinating market located at each of the grid supply points (GSP), the physical interface between the distribution and transmission network, located at $132 \mathrm{kV}$ in England.

This is realised through a pay-as-clear pool market, a balancing and ancillary market at each of the GSPs which is governed by the evolution of the current distribution network operator (DNO), known as the distributed service provider (DSP) [22]. These 'local' markets bring forward regional differences to indicate to investors where on the network a specific technology and services would be valued. These are not to be confused with local energy markets (LEMs) which are private platforms operated by third parties such as Centrica [33]. The national wholesale market is also reconfigured to increase investment certainty to both variable and flexible technologies located on both the distribution and transmission network through amendments to regulation and trading arrangements. The electricity market design operates over a broad timescale, from years in advance up to the delivery of the traded electron. The timescale of focus for this proposed design is that of the SPOT, i.e., $48 \mathrm{~h}$ up to, and including, the delivery of the contracted service. This paper also proposes reconfigurations to the balancing and ancillary markets within this timescale. The rationale for focusing on this timeframe is underpinned by the importance of operating closer to real time for variable renewable energy (VRE) generating assets, as this permits more accurate forecasting and allows one to re-position themselves to mitigate imbalance charges $[40,41]$. The importance of the Day Ahead (DAH) and Intraday (ID) market will continue as trading closer to delivery will become increasingly critical [41].

The proposed re-configuration of GB's electricity market design in this paper builds upon and consolidates 30 proposed electricity market designs within liberalised electricity sectors to create a strawman design. Building on similar approaches taken elsewhere [11,42], this design was reviewed and critiqued by academics, governmental representatives and industry experts to appraise, refine and validate the proposal. 
The proposed design was guided by a smart energy system (SES) approach which coordinates across the three pillars of energy (electricity, mobility and heat) to identify synergies between these in order to provide an optimal solution to both the individual sector, and the overall energy system $[43,44]$. As such, multiple alterations to the electricity market design are proposed which facilitate the integration of services, i.e., flexibility, from both the heat and mobility sector [6,43-46]. Therefore, the proposed design promotes the belief that a provider of a service should be able to access the market based upon the provision of said service, not basing market access on the characteristics of the underlying technology. This means that the proposed electricity market design fits within the wider institutional governance of the energy sector change by harmonising across the electricity, heat and mobility sectors-in other words, it is one dimension of a whole-system solution for energy transformation.

The paper proceeds as follows. Section 2 reviews the literature to justify the need for a reconfiguration of GB's electricity market design. Section 3 introduces the methodology used within this study. Section 4 details the proposed electricity market design, and Section 5 provides concluding remarks and proposed areas for further studies.

\section{Literature Review}

The objective of this literature review is to evidence that the efficacy of GB's electricity market design has diminished and necessitates a reconfiguration. This argument is based upon the following segments. Firstly, the objectives of the electricity market design introduced at the time of privatisation, whilst still paramount, must be underpinned through means which also aid in the facilitation of net zero. Secondly, in terms of the issues, but also the benefits, stemming from the deployment of distributed technologies with new modes of operation unlocked via digitalisation, the former can be resolved, whilst the latter can be exploited through re-design. Thirdly, the skewed economics of the electricity sector, known as the distribution gap, which can be evidenced by events brought forward by COVID-19, will be explored.

\subsection{Market Objectives and Market Design Implementation}

The liberalisation of Britain's electricity supply industry in 1990 signified a transition away from public ownership of the Central Electricity Generation Board-a move away from a monopoly to a private market driven system $[47,48]$. The objectives of the introduced market design were to deliver secure, reliable electricity efficiently and at competitive prices [47,49]. The means of achieving these objectives would ideally be met by technologies and services which align with net zero. As will be evidenced in the following section, the technologies and services exist but the market design must be reconfigured to exploit these [26,50-52].

The rules underpinning the electricity market design evolve in a continuous process in which stakeholders may play an important role [52], assuming their collected and consolidated views are used to aid and inform those with the agency to enact the eventual market design re-configuration. A recent example is the Council of Australian Governments [53] in Australia which called for feedback from interested parties on possible solutions to the falling efficacy of their electricity market design. The value of this paper is the consolidation of expert views on how the future electricity market design should be structured, the outcome of which is detailed in Section 4. This is not a quantitative analysis of the proposed design, though mathematical modelling would add to the validity. 


\subsection{Technological Developments Have Led to Concerns over the Efficacy of the Electricity Market Design}

The deployment of variable, zero-carbon technologies onto both transmission and distribution networks has been supported by both national and EU policies to encourage reductions in greenhouse gas emissions. Policies such as the Renewables Obligation, the feed in tariff, and the Contract for Difference (CfD) have brought forward learning gains with the increased levels of deployment resulting in greater technical and construction experience. This in turn has decreased operational costs and increased the efficiency of these generating assets $[2,54]$.

Between 2010 and 2019, the share of renewable generation in total electricity generation in the UK increased fourfold, and in 2019 renewables contributed $37.1 \%$ of total electricity generation - the first time these generators have provided over one-third of total electricity generation [55]. During the same time period, the share of fossil fuels decreased by $51 \%$, with many conventional generators losing their market share to VRE generating assets [55]. This trend is likely to continue, with National Grid ESO's 2020 Future Energy Scenarios (FES) estimating that by 2030 , up to $71 \%$ of total electricity generation within GB is expected to be at zero-marginal cost, rising to $80 \%$ by 2050 [6]. This FES also estimates that by 2050 , $42 \%$ of generating assets will be connected to the distribution network $[6,56]$. This trend has brought forward many issues but also many benefits which can be exploited as reviewed in Sections 2.2.1 and 2.2.2, respectively.

\subsubsection{Issues}

There are multiple issues stemming from this technological shift, and more broadly from operating a bilaterally based market structure (Table 1). These are likely to become exacerbated with the further deployment of zero-marginal cost generation and DER. These issues are revisited in Section 4, Table 5, which explains how the proposed design can aid to mitigate these issues.

Table 1. Summary of several issues associated with the current electricity market design.

\begin{tabular}{|c|c|}
\hline Issue & Summary \\
\hline Missing money & $\begin{array}{l}\text { The dispatch of generating assets is determined by their Operational Expenditure (OPEX) } \\
\text { cost, principally the fuel element [2]. As more efficient thermal assets enter the market with } \\
\text { lower OPEX costs, the older units are displaced. This phenomenon is exacerbated by } \\
\text { variable generating assets with low OPEX cost due to the removal of the fuel element, } \\
\text { displacing the more expensive technologies }[42,57,58] \text {. This results in a lower capture rate } \\
\text { for those still required to meet demand, decreasing the incentive to invest in technologies } \\
\text { reliant upon a sustained clearing price, leading to concerns over long-term capacity } \\
\text { adequacy }[21,59,60] \text {. }\end{array}$ \\
\hline Price cannibalisation & $\begin{array}{l}\text { High VRE output can displace thermal generators with higher OPEX costs, lowering the } \\
\text { clearing price and reducing the VRE capture rate [61-63]. This increases the risk for those } \\
\text { operating in the market without a form of revenue assurance scheme such as the } \\
\text { CfD }[57,61] .\end{array}$ \\
\hline Lacking flexibility & $\begin{array}{l}\text { Despite agreement on the requirement for flexibility by governmental bodies, economic } \\
\text { regulators, system operators, academics and industry bodies, to date, only the balancing } \\
\text { and ancillary market provide value for flexibility as a service [64,65]. Furthermore, neither } \\
\text { the CfD nor the capacity market were designed for the procurement of flexible services. The } \\
\text { CfD addressed long-term investment into low-carbon generation, whereas the capacity } \\
\text { market was designed to only respond to the system adequacy challenge and not the } \\
\text { emergent flexibility adequacy challenge [56,63,64,66]. Additionally, in securing system } \\
\text { adequacy, the capacity market has reduced the prevalence of scarcity events in which prices } \\
\text { would rise as the margins between supply and demand converge, raising the market } \\
\text { clearing price [67]. These events provide the signal for possible revenue stream for } \\
\text { flexibility from demand-side assets as they can reduce one's demand during these } \\
\text { high-priced events, or generate an income based on the arbitrage opportunities [31]. }\end{array}$ \\
\hline
\end{tabular}


Table 1. Cont.

\section{Issue}

Lacking transparency

An estimated $85 \%$ of GB electricity is traded bilaterally in which the volumes and prices are not within the public domain, only accessible through a subscription to a price reporting agency [68-70]. This opaque structure dampens investment signals as the financial compensation received for a service is not known, which may also result in the cheapest technology not being dispatched $[40,71]$.

The increased deployment of DER evidences the need to reflect regional geographies within the electricity market design. However, GB operates under a single price bidding zone, with price formation at the national level [72]. This does not reflect local

Not reflecting changing energy geographies characteristics such as the scarcity or surplus of electricity within a constrained area of the network [20,73]. Reflecting 'local' network conditions would signal where on the network value could be realised by providing a specific service, i.e., flexibility. Solving locational issues with either generating or demand-side assets or services in close proximity via a local market would support their integration, helping to conserve the profits from these services in the local economy, which may also encourage new investment into DER [12,13].

\subsubsection{Potential Benefits to Be Exploited through Electricity Market Design} Re-Configuration

Facilitating net zero is considered to be underpinned by zero-carbon, variable and often distributed technologies such as onshore wind $[6,8,65,74,75]$. As such, the electricity market design would ideally evidence the investment potential in technologies and services which provide flexibility to counteract variability [76] alongside DER to unlock the following benefits:

(1) Reducing balancing costs through the displacement of more expensive, and carbonintensive forms of flexibility such as an open-cycle gas turbine [77].

(2) Network operators, through schemes such as active network management, can defer costly network reinforcements by utilising consumer flexibility to minimise the breaching of network operational limits [14-18].

a. Furthermore, these relatively small investments into flexible demand-side assets can postpone decisions on larger investment until more evidence is collected, reducing the scope for making potentially high regret decisions [77-79].

(3) Locating flexible services near to, or co-locating with, VRE generation can mitigate the extent of price cannibalisation by absorbing excess VRE and reinjecting at times of increased demand. This reinjection will likely coincide with higher power prices, resulting in a more profitable capture rate [80].

a. This has an added benefit of reducing network constraints via the removal of the excess electrons on the network. By storing, and not curtailing this zerocarbon generation, when reinjected this removes the need for carbon-intensive technologies which may have been otherwise required [80].

(4) Regional geographies will become increasingly important under a decentralised electricity system. Local balancing can be facilitated through the deployment of generation and demand in proximity on the network. This removes the distance that electrons would otherwise travel and possibly breach network capacity in doing so, thus leading to a more efficient use of the network $[9,20,21,45,78,81]$.

These benefits can be realised through the deployment of locational market $[7,45]$. 


\subsection{The Distribution Gap}

The legacy of an electricity market design based upon the then present characteristics of centralised, large-scale and top-down operation has led to a distribution gap [22,33]. The distribution gap refers to the void of institutional framework at the distribution network, as this level was often considered 'passive' and only 'drew' from the transmission level where the majority of centralised generating assets were located [8]. However, as evidenced by Section 2.2, the electricity landscape is undergoing a fundamental shift, with electricity generated from within a GSP increasingly being exported onto the transmission network [82]. Yet, the legacy of operating a centralised electricity market design has skewed the economics of the electricity sector, limiting the value for services which DER can provide. This can be evidenced by recent events brought forward under COVID-19.

\subsubsection{COVID-19}

Both international and domestic imposed lockdowns in response to COVID-19 led to dramatic shifts in electricity consumption patterns [83-87]. All European countries experienced a significant overall decline in demand for electricity due to population containment measures except Sweden, which imposed 'soft' confinement measures [85]. Overall demand in Sweden remained consistent with pre-COVID-19 levels, which has been attributed to demand from certain sectors of the economy decreasing, such as transportation, being offset by increases in residential buildings [88].

In GB, actual electricity demand was $~ 20 \%$ less than National Grid ESO's predictions, whilst Q2 2020 saw a $+32 \%$ increase in the share of renewables compared to Q2 of $2019[89,90]$. The higher renewable output led to major challenges in absorbing this variable generation, leading to the increased cost of balancing actions and the continued dampening of the wholesale power price [91,92]. These trends were expected by 2030, yet conditions brought forward by measures in response to COVID-19 during the summer of 2020 provide a glimpse into the future electricity sector [91]. As such, the actions taken this summer provide insights into inefficiencies within GB's current electricity market design under a scenario akin to net zero.

The distribution gap can be evidenced by two events over the summer months of 2020. First, National Grid ESO raised modification GC0143: Last Resort Disconnection of Embedded Generation in response to the decrease in demand. Their rationale for the decision was based on forecasts that only generation from non-flexible units such as nuclear and embedded generators would limit the ESO's ability to maintain the security of supply [93]. This modification permitted the ESO to instruct a DNO to disconnect embedded generation without financial compensation [86,93].

As embedded generators have not historically been utilised by National Grid ESO to balance the grid, they therefore do not have a connection agreement with them, and can't be activated and financially compensated by National Grid ESO, unlike their transmissionconnected counterparties [93]. Therefore, in the scenario of being disconnected under GC0143, they would not receive financial payment despite their service providing a value to the network. As such, this poses financial risk to embedded generators which their transmission-connected parties would not be exposed to, demonstrating the skewed nature of the electricity economics against DER.

Whilst GC0143 demonstrates the distribution gap, the introduction of Operation Downward Frequency Management (ODFM), a temporary service between May and October 2020, highlighted the significant role of distributed generating and demand-side assets in offering flexibility to balancing the grid. Between May and October 2020, GC0143 had not been issued as National Grid ESO designed and implemented ODFM [94]. This temporary service allows National Grid ESO to contract with technologies outside of the balancing market, typically embedded generation, previously invisible to National Grid ESO due to the lack of contractual agreement [94]. Over $4.5 \mathrm{GW}$ of predominantly embedded solar and onshore wind has signed up to this service with just under $5 \mathrm{GW}$ of ODFM being utilised in May 2020 alone [94,95]. ODFM evidences how distributed 
connected VRE generating assets can contribute to balancing services and receive financial compensation for providing their flexibility. This temporary route to market indicated that it is possible to realign the electricity economics to a level playing field.

The current electricity economics has to date aided the lock in of thermal generators as these generating assets are remunerated, justifying future investment which is not the case for their distributed counterparties $[27,96]$. However, this does not need to be the case. The electricity market design is a social construct and therefore this institution can, and has been, reconfigured in response to concerns over the efficacy of the current design as demonstrated by the introduction of ODFM [97].

\subsubsection{Pursuing a Smart Energy System Approach}

The electrification of both the heat and mobility sector through the deployment of demand-side assets, such as heat pumps and electric vehicles (EVs), provide additional forms of flexibility to be exploited if the market design permitted [43,44]. In utilising embedded demand-side assets for their flexibility, ODFM (and indeed many other trials such as WPD's Electric Nation [98], Oxfordshire's project LEO [99] and those awarded Innovate UK funding for Vehicle to Grid services [100]) demonstrate the novel means of providing additional flexibility to the network [6]. The application of these demand-side assets demonstrates the value in 'plugging' this distribution gap and they are making strides towards doing so.

This practice is referred to as a smart energy system (SES) approach within the literature, which offers access to increased flexibility and storage capacity which are vital for the integration of VRE at scale [6,43-46]. The SES approach, which utilises both mobility and heat as flexible load, may provide cheaper alternatives than an electrical counterpart $[44,101]$. Therefore, there are clear associated benefits of a SES approach but in order to facilitate the deployment of these flexible demand-side assets, there needs to be a clear route to market which identifies the value for their services [43,44,101].

Despite the aforementioned importance of pursuing a SES approach, the current electricity market design hinders the ability to do so. For example, National Grid ESO, in their 2020 FES, forecast 38.5 GW of vehicle to grid flexibility by 2050 [6], which is required to underpin a high renewable future, but facilitating this will require alterations to the existing market design. This has been recognised within National Grid ESO's 'wider access to the balancing market' campaign, which has eased the access of flexibility providers into the balancing market through the design and implementation of the virtual power plant [102]. This permits aggregators of EV load to enter into the balancing market, as is being pioneered by Flexitricity [103]. However, virtual power plant status does not permit access into the wholesale market, limiting sources of additional income. Furthermore, EVs are not permitted to compete for capacity payments under the current capacity market regime as they are not recognised as a 'generating technology class' [104]. In securing an additional revenue scheme through the capacity market, this would increase the investment opportunities into EVs, yet this is not currently permitted, reducing the attractiveness for possible investors. While progress is being made within the mobility sector, the utilisation of flexibility from heating is still in its infancy [46,101]. Therefore, as will be detailed in Section 4, the local balancing and coordinating markets reduce the barriers to market entry for smaller-scale technologies which will likely be the EVs and those with heat load in order to provide an more suitable route to market and a means to provide their flexibility.

Though future reference to the 'electricity market design' will be made, this is with the inclusion of the mobility and heat sectors alongside other electricity intensive industries which can provide grid services. 


\section{Methodology}

This section details the methodology employed within this research, which led to the creation of an industry appraised electricity market design proposed in Section 4 .

A systems thinking approach guided this research. Systems thinking takes as a starting point that systems are greater than the sum of their parts, and emphasises the importance of studying the dynamic interconnections between system components and the resultant 'emergent' behaviours of systems [105-107].

The relevance of incorporating a systems thinking approach within this study was twofold. Firstly, the electricity market design is conceptualised as a set of interconnected modules, each with their own function but when brought together constitute the electricity market design, i.e., the system is greater than the sum of its parts (See Section 3.2 for more details). Secondly, and as will be discussed in Section 4.7, with the shift from a predominantly centralised, top-down electricity system to one where both centralised and decentralised technologies are to coexist, facilitating the coordination between actors across the network will be critical to the efficient operation of the electricity market design. The need for coordination between system components is recognised within the systems thinking approach. Furthermore, this approach has been implemented in three previous publications on alternative electricity market designs $[42,106,108]$, indicating the relevance of systems thinking within this field of study.

This methodology consisted of 4 stages.

\subsection{Stage 1: Review of Previously Proposed Market Designs}

The authors identified 30 proposed electricity market designs published since the turn of the century for liberalised electricity systems across the globe, sourced from a range of grey and academic literature(s). Each reviewed proposal had an issue statement which guided their solution through re-design, i.e., [109] proposed a local flexibility market as a means to procure flexibility to mitigate costly network reinforcements. When appropriate, these solutions were incorporated into the proposed design following the selection criteria detailed in Section 3.3.

\subsection{Stage 2: Modularisation of GB's Electricity Market Design}

Electricity market designs can be understood as a set of interconnected modules which individually serve a specific purpose, yet these modules when brought together constitute to the electricity market design. For example, the balancing market module is to ensure that generation and demand are consistently equal. However, the actions required by this module relate to the outcome of the wholesale electricity market module in determining the scale of balancing actions which will be required. As such, it is not just the individual modules which are important but the coordination between them.

In order to analyse the efficacy of the market design, the technique of 'modularisation' was employed $[110,111]$. This entails the identification and separation of the core components, known as modules, of the system in question. This process provides three key insights $[110,111]$. Firstly, separating a system into modules allows for the evaluation of the efficacy of each module in isolation. Secondly, this allows the coordination between each of these modules to be reviewed. Thirdly, in reviewing the two aforementioned insights, it provides an overview of the efficacy of the overall system.

Modularisation has been utilised in previous research to identify perceived issues with specific modules, and the coordination between them, enabling the authors to propose bespoke solutions. Franco et al. [112] utilised this approach to explore the different modules introduced during the Electricity Market Reform in GB, whereas Peng and Poudineh [42] and Roques and Finnon [21] identified and addressed inconsistencies between the existing modules of an electricity market design and those newly introduced. Their rational for a modular approach stems from the ability to provide a holistic overview of the electricity market design, whilst evaluating each module in isolation, so as to not leave 
any assumptions on neglected modules and assess the join performance of all modules together.

\subsection{Stage 3: Construction of a Strawman Design}

Identified issues were attributed to specific module(s), the coordination link between these, or highlighted where a new function was required, resulting in the introduction of a new module. The current modules of GB's electricity market design were then reconfigured by incorporating many of the proposed solutions reviewed in Section 3.1.

In reconfiguring the electricity market design, the authors altered the existing module(s) through one of the three following processes:

(1) Augmentation: Introducing a new module to an existing system which embodies new concepts, addressing a specific need currently not catered for.

(2) Layering: The process of new rules being attached to an existing module, to provide an additional function.

(3) Exclusion: Removing a module which is no longer required.

Table 3 details which process was applied to each module.

The selection process for whether proposed solutions identified in Section 3.1 were to be incorporated was determined by whether the proposed solution:

(1) Rectified an issue in line with the objectives of this design,

(2) Had any knock-on impacts on fellow modules or the coordination between them, and

(3) Could be implemented alongside other proposed solutions.

a. This created the strawman design which then underwent evaluation (Section 3.4).

\subsection{Stage 4: Appraisal and the Validation of the Strawman Design}

The strawman design was appraised by industry experts via 35 semi-structured interviews with a range of stakeholders from both GB and Denmark (Table 2).

Table 2. Interviewee shareholder groups.

\begin{tabular}{clcc}
\hline & \multicolumn{2}{l}{ Representative } & \\
\hline Academics & 9 & LEM representatives & 2 \\
\hline Consultants & 3 & Trade associations & 2 \\
\hline Incumbent energy supplier & 3 & Transmission system operator (TSO) & 1 \\
\hline Think tank & 3 & Distributed system operator (DSO) & 1 \\
\hline BSC implementor & 2 & European energy regulator & 1 \\
\hline Energy economic regulator & 2 & SME energy supplier & 1 \\
\hline Electricity traders & 2 & DER installer and optimiser & 1 \\
\hline Government representatives & 2 & & \\
\hline
\end{tabular}

Interviewees from Denmark were selected for two main reasons. Firstly, they were selected due to their pioneering research on the SES approach $[43,44]$, which provided useful insights into how this could be applied to the proposed market design in Section 4. Furthermore, Denmark is considered a 'world leader' in the transition towards an economy underpinned by VRE $[113,114]$. Therefore, the lessons learnt throughout their pioneering transition provided insights on the requirements of a future electricity market design which were incorporated into the proposal.

However, the two countries operate different electricity market designs. For example, GB operates under a national pricing system with a single price for electricity, whereas there are two pricing zones in Denmark, with the price of electricity differing dependent upon congestion between these zones $[67,115]$. Whilst these differences limit the scope for a direct comparison between the two market designs, the proposed design in Section 4 
attempts to identify regional differences in the price of electricity. Due to the zonal model of Denmark, there were useful insights from interviewees in terms of how to shape the market design to emphasise these regional differences.

These experts were selected based upon their involvement within the electricity market. For example, academics had published on the electricity market design, consultants had produced working papers on this topic, and energy suppliers were actively involved within the markets.

The proposed strawman design, the outcome of Stage 3, was appraised by 35 industry experts in semi-structured interviews. Interviews centred on discussion of the proposed design and provided opportunities for interviewees to identify aspects of the design requiring further alteration. Follow-up interviews were held to confirm subsequent alterations to the proposed strawman design.

Furthermore, respondent validation was employed to ensure that the views of the interviewees collected were accurate [116]. Interviews were recorded and verbatim transcripts were provided to the interviewee before any element was incorporated. This process allowed each interviewee the opportunity to provide feedback on the transcript, ensuring their views were accurately captured and where necessary, make amendments.

This provided a breadth of views on the proposed electricity market design detailed in the following section, including the feasibility of the proposed design alongside how the proposal, in their expert view, would perform against the objectives.

Transcripts from the semi-structured interviews were coded to identify the interviewee views on each of the proposed modules, the coordination between them and the efficacy of the overall electricity market design. If a respondent viewed an alteration to be insufficient, further discussions were held to firstly understand their rationale and secondly to identify a possible solution.

\section{The Market Design}

This section introduces and discusses the proposed electricity market design for GB.

\subsection{Objectives}

As explained in Section 2.1, emphases on efficient delivery of secure, reliable electricity at competitive pricing can be understood in the context of market liberalisation. However, the facilitation of net zero requires the reappraisal of the market design in how these objectives are achieved [50-52]. Achieving net zero would ideally be met in an equitable manner, with all market participants connected to either the distribution or transmission network being able to offer in their services and be rewarded for doing so. As evidenced by Section 2.3, this is currently not the case.

This section proposes a set of market design reconfigurations to aid in facilitating these objectives in line with net zero.

\subsection{Overview of the Design}

The proposed electricity market design consists of six interrelated modules as illustrated in Figure 1:

- Module 1: The DSP pool market,

- Module 2: The DSP ancillary market,

- Module 3: The DSP balancing market,

- Module 4: The wholesale market,

- Module 5: The independent integrated system operator (IISO) ancillary market, and

- Module 6: The IISO balancing market. 


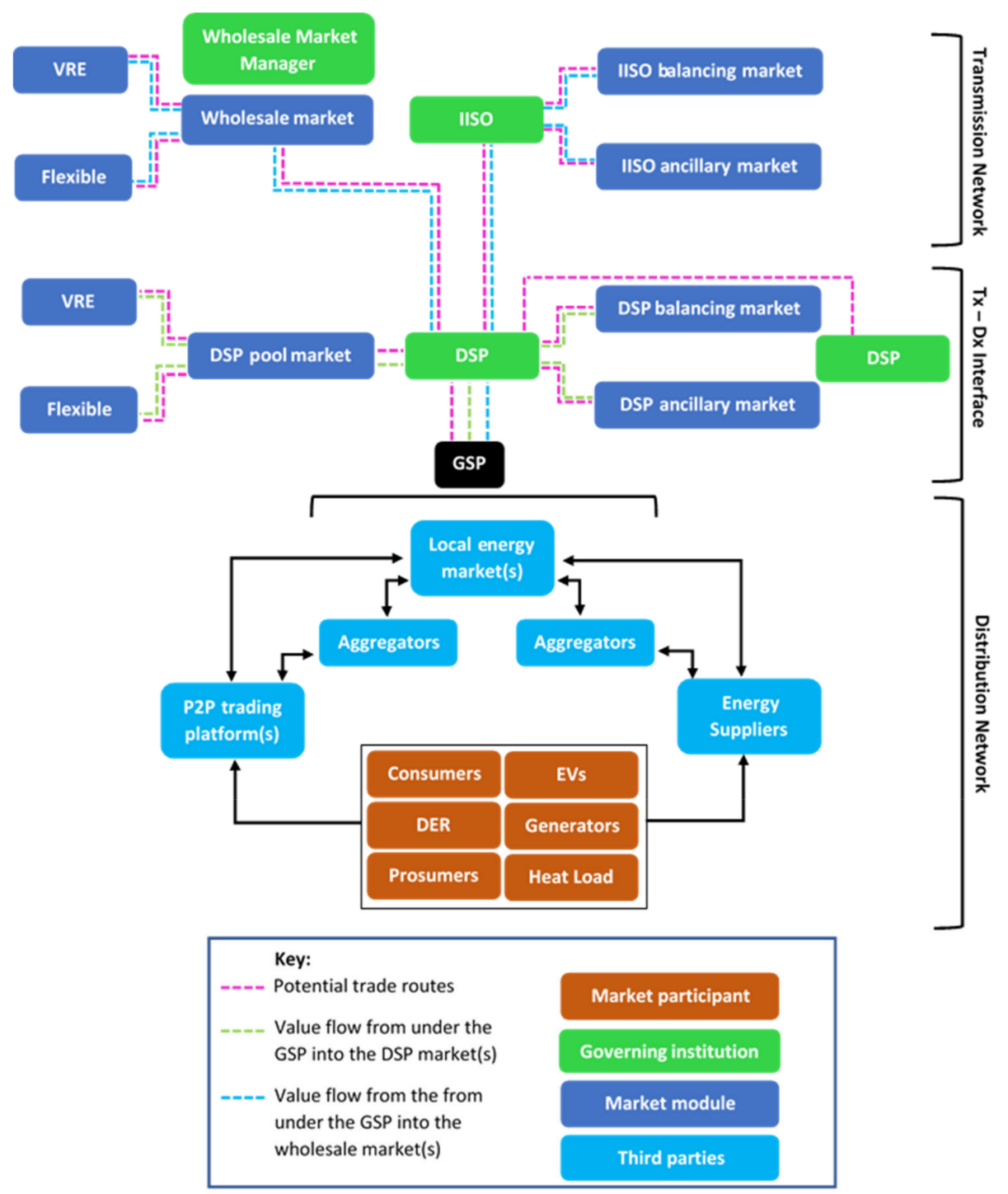

Figure 1. Schematic of the proposed electricity market design with potential trade routes, value from the GSP into the DSP and wholesale market identified. Only one GSP for illustrative clarity. In reality, there would be multiple GSPs within a DSP's geographical remit. Entities listed within a GSP are not an exhaustive list, but a representation of several likely parties to be operational within this geographical area. Tx and Dx refer to transmission network and distribution network, respectively. Market participants refer to generating or demand-side asset(s), such as prosumers, EVs and those with flexible electrified heat load. Authors' own.

Each of these modules operate in parallel, with actions taken within one module impacting upon another. It is therefore essential that there are clear, established routes for coordination between modules to avoid conflicting actions being taken. The following section will delve into the purpose of each of these modules independently, before detailing how these modules shall be coordinated in Section 4.7.

Specifics on each module are summarised in Table 3. 
Table 3. Each module, how they were reconfigured and the specifics of the module. Authors' own.

\begin{tabular}{|c|c|c|}
\hline Module & Re-Configuration & Specifics \\
\hline The DSP pool market & Augmented & $\begin{array}{l}\text { Procurement method: Auction } \\
\text { Timescale of procurement: } \\
\text { DAH/ID } \\
\text { Clip size: } 0.05 \mathrm{Mw} \\
\text { Settlement: Pay as clear }\end{array}$ \\
\hline The DSP ancillary market & Augmented & $\begin{array}{l}\text { Procurement method: Auction } \\
\text { Timescale of procurement: } \\
\text { DAH/ID } \\
\text { Settlement: Pay as clear } \\
\text { Clip size: Product specific. No } \\
\text { higher than } 0.1 \mathrm{MW}\end{array}$ \\
\hline The DSP balancing market & Augmented & $\begin{array}{l}\text { Procurement method: Utilising } \\
\text { bids/offers } \\
\text { Timescale of procurement: } 5 \text { min } \\
\text { window before the opening of the } \\
\text { IISO balancing market (Module 6) } \\
\text { Settlement: Pay as clear } \\
\text { Clip size: } 0.05 \mathrm{Mw}\end{array}$ \\
\hline
\end{tabular}

\begin{tabular}{|c|c|c|}
\hline The wholesale market & Layered & $\begin{array}{l}\text { Procurement method: Auctions } \\
\text { Timescale of procurement: } \\
\text { DAH/ID } \\
\text { Settlement: Pay as clear } \\
\text { Clip size: } 0.1 \mathrm{MW}\end{array}$ \\
\hline The IISO ancillary market & Layered & $\begin{array}{l}\text { Procurement method: Auctions } \\
\text { Timescale of procurement: } \\
\text { DAM/ID } \\
\text { Settlement: Pay as clear } \\
\text { Clip size: Product specific. No } \\
\text { higher than } 0.1 \mathrm{MW}\end{array}$ \\
\hline The IISO balancing market & Layered & $\begin{array}{c}\text { Procurement method: Utilising } \\
\text { bids/offers } \\
\text { Timescale of procurement: Real } \\
\text { time } \\
\text { Settlement: Pay as clear } \\
\text { Clip size: } 0.1 \mathrm{Mw}\end{array}$ \\
\hline The capacity market & Excluded & $\begin{array}{l}\text { Rationale for exclusion discussed in } \\
\text { Section 4.8. }\end{array}$ \\
\hline
\end{tabular}

\subsection{The Electricity Market Design}

\subsubsection{Regulatory Changes}

Regulation is not an explicit aspect of the electricity market design, though their design impacts upon investor confidence and influence the behaviour of those who own and operate within the market $[117,118]$. Priority dispatch for VRE, and alterations network charges are introduced to provide investment confidence whilst financially encouraging close proximity between market participants and intended load.

\section{Priority Dispatch for VRE}

Priority dispatch, the obligation for the TSO to dispatch VRE before their thermal counterparties is placed on the TSO, known henceforth as the independent integrated system operator (IISO), DSPs and the wholesale market manager. This is to facilitate the two market tiers alongside utilising zero-carbon technologies for ancillary and balancing services where feasible. Though VRE will typically be dispatched first due to their near 
zero marginal costs, priority dispatch provides further reassurances to investors that their VRE generating assets will be utilised $[59,118]$.

\section{Network Charges}

Transmission network use of system (TNUoS) and distribution use of system (DUoS) which recover the cost of providing and maintaining the infrastructure which transports electricity across the country are reformed [119]. Currently, these charges are socialised, which does not incentivise contracting with a counterparty who is geographically close on the network [120]. The specifics of such a reform are outside the scope of this paper, but the principle aim would be for these charges to correspond to the distance of the network used in the facilitation of a trade, i.e., requiring the distribution network would incur DUoS charges, but not TNUoS. With all participants within a GSP connected to the distribution network, they would be financially stimulated to contract with counterparties within their GSP.

\subsection{The DSP}

Modules 1-3 are introduced to facilitate the local balancing and coordinating market. Prior to delving into each of these modules, the DSP, and their remit, will be further explored.

The DSP is an evolution of the current DNOs operational within GB, combining the existing functions of the management of networks with system operations and the role of facilitating the local balancing and coordination market [22]. Under their license condition, the DSP is required to balance their geographical region which is realised through the implementation and operation of the DSP pay-as-clear pool market, the DSP ancillary and balancing market for each GSP within the DSPs region, which all operate under the SPOT timescale (Modules 1-3).

\subsubsection{Module 1: The DSP Pay-As-Clear Pool Module}

This proposed augmentation introduces a pool market settled by an auction based upon the pay-as-clear principle. Each of these pay-as-clear pool markets is located at the GSP, and as such a single DSP institution may govern several of these pay-as-clear pool markets.

A pool market was selected due to its suitability for VRE generating assets as detailed in Table 4-factors which are beneficial to smaller market participants who will likely be entering into the DSP pay-as-clear pool market. An auction was selected as the clearing mechanism over continuous trading due to favouring smaller market participants. This stems from the standardisation of contracts and the predetermined trading times, which in theory should reduce the burden of expertise and constant monitoring of the market compared to continuous trading $[40,121]$.

Table 4. The rationale for selecting a pool market as opposed to only self-dispatching. Source: $[20,21,24,40,58,122]$.

Structure

Structure

Suitability for VRE

Transparency

\section{Pool}

Reduced risk of facing imbalance charges as a result of a central market which pools liquidity. This promotes the ability for VRE generators to procure, or sell, depending upon the environmental conditions which may result in deviations from contracted positions.

Due to standardised products, trades can operate on a faster timescale allowing them to occur closer to real time compared to continuous trading. This also allows VRE to react to fluctuations in output due to environmental conditions and mitigate imbalance charges.

Uniform price auction provides transparency and ensures that the least expensive and most efficient generating unit or service is dispatched.

Market prices are visible to buyers/traders/sellers. 
This market structure is reflective of the distributed locational marginal price (DLMP) as proposed by $[7,38,123]$, with each node located at the GSP. The DLMP structure has been introduced owing to the ability to bring forward the value of location, maximise the value received by DER and bring forward investment into both generating and demand-side assets at the end of the grid $[7,21,31,124,125]$. The merits and possible applications of a DLMP market structure have been modelled by various published works such as $[7,38,123]$. For example, [7], models an organised DLMP market structure for each of the nodes within a distribution network as a means to aid in coordinating actions taken between the DSO and TSO; [38] models a new local energy market within the distribution systems to integrate peer-to-peer (P2P) trading and probabilistic DLMP pricing; [123] models a DLMP market structure to alleviate congestion brought forward by the deployment of EVs, a useful element considering the support of an SES approach within the proposed conceptual framework. Liquidity within the DSP pay-as-clear pool market may be a concern due to reducing the geographical network through the DLMP approach, and by proxy also reducing the number of market participants. Yet, the adoption of a SES approach should increase the number of participants within the GSP as many of the electrified technologies, namely heat pumps and EVs, will be connected within a GSP.

Each of these DSP pay-as-clear pool markets would operate under a two-tier market structure. The first tier is for VRE generating assets, whilst the second is for the procurement of flexibility.

The DAH and ID auctions held by each DSP pay-as-clear pool market would identify the forecasted output of VRE generating assets (due to priority and grid dispatch) and would compare this to forecasted demand revealed in that auction. Any shortfalls of VRE output compared to demand are then met by the flexibility market, which opens post auction result and is dedicated to the procurement of flexibility from the electricity, heat and mobility sectors. If bids into the flexibility market are higher than the clearing price for the initial VRE auction, this would raise the overall clearing price within the GSP for that settlement period.

The clearing price for each of the DSP's pay-as-clear pool markets will differ based upon a range of factors including the technologies present within that node, the environmental conditions dictating VRE output, the level of demand needing to be satisfied within each regions and the short run marginal costs of those competing within the flexibility market [126]. Transmission-connected technologies are not permitted to enter into the DSP pay-as-clear pool market. However, their services may be indirectly procured if the DSP buys a specific service from the wholesale market, or the IISO's ancillary and balancing market.

\subsubsection{Operating within Module 1}

Market participants located within a GSP voluntarily conduct trade into the pay-asclear pool or with other participants within their GSP for generation, consumption or flexibility and, in principle, there are no restrictions on whom one may conduct trade with in their GSP region (Figure 1).

These market participants, located on a distribution network within the GSP, can conduct trade into this DSP pay-as-clear pool market or through novel means such as P2P platforms, LEMs, aggregators and suppliers. This is not an exhaustive list of markets operated by third parties as new and innovative business models may emerge in response to the new routes to market for DER.

This is reflective of a 'voluntary' pool structure in which market participants and their counterparties can agree bilateral contracts but shall inform the DSP of these to aid in scheduling. All forecasted trades are to be known by the DSP who will ensure that resulting power flows do not destabilise the grid.

Relevant data on all trades facilitated within the GSP, either into the DSP pay-as-clear pool market or bilaterally between market participants, will be publicly available, with confidential data being omitted/anonymised. This practice is evidenced by PicloFlex, a 
third party operated marketplace for the tendering of flexibility within GB facilitates access to a wide range of competition and bidding data, detailing the availability and utilisation fee, the capacity offered, the time of activation and an indication to where on the network the successful assets are located [127]. This transparency will generate substantial volumes of data revealing the value received from the performing of a specific action, i.e., providing flexibility. Such detailed information would enable a project manager to analyse whether an investment into a specific technology or provision of service in a certain area on the network would lead to a sufficient return on their investment.

Facilitating end-user services, such as flexibility, may not require time, effort and expertise as these services can be automated through the combination of artificial intelligence, internet enabled technologies and novel third-party businesses who can provide this service whilst extracting value for themselves and the end users [17,128].

\subsubsection{Module 2: The DSP Ancillary Market}

The deployment of geographically distributed technologies in parallel with IoT provides the means for these to solve local grid issues such as congestion management, voltage control and reactive power to the benefit of both DSP and the IISO [7,11,17,129,130].

The feasibility is exemplified by existing projects such as UKPN's Power Potential which utilises DER to resolve transmission voltage and thermal constraints through the increased coordination between UKPN and National Grid ESO [131-133].

The DSP ancillary market would operate transparent auctions held at the DAH and ID timescales for specific services for each of their GSPs. This direction is currently in motion within GB, as evidenced by the a recently reformed product suite by National Grid ESO, one of these, Dynamic Containment, being procured at the week ahead, but with intention to procure daily [132].

At times, it may not be possible to source the required service to solve grid-specific issues from within the same GSP that the issue is located. Instead the DSP may need to call upon market participants from other GSPs within their region or procure from neighbouring DSPs or the IISO ancillary market, introduced in Section 4.5.

Determining when a DSP would instruct a market participant outside of their geographical remit to aid in the provision of an ancillary service would be based upon an algorithm which could factor in aspects such as:

- Associated carbon,

- The distance of the technology from load, and

- Any arising network issues from such a dispatch and the cost of procurement.

The nuances of such an algorithm are outside the scope of this paper.

\subsubsection{Module 3: The DSP Balancing Market}

In addition to an ancillary market, the DSP will also operate a balancing market for each of their GSP regions. Market participants would provide bids and offers to the DSP stating the price they would require to either increase or decrease demand/generation. At times, it may not be possible to balance a GSP with the technologies located within this geographically confined area of the network. Similarly to Module 2, an algorithm would also be designed to determine when to instruct a market participant(s) out of their geographical remit.

\subsection{Module 4: The Wholesale Market}

The wholesale market is operated by a dedicated wholesale market manager, whose remit is to ensure transparency in prices by also operating a two tier market structure reflective of the DSP pay-as-clear pool market. The standardisation of these two marketplace structures will support the facilitation of distributed technologies, and services located within a GSP node into the wholesale market $[65,134]$. This route to market may be utilised if it is believed that there is a higher capture rate for trading into the wholesale market rather than their respective DSP pay-as-clear pool market. 


\subsection{The IISO}

Modules 5-6 are governed by the IISO, an evolution of National Grid ESO [22]. The IISO is an independent and non-profit system operator who would oversee the electricity, heat and transport sectors at both the transmission and distribution networks [22,135].

The specific remit of the IISO in relation to this electricity market design is principally to ensure that the entire grid is constantly in balance. The IISO facilitates this through operating the reformed IISO ancillary and IISO balancing market (Modules 5-6). The IISO will principally be reviewing the transmission-connected generation and demand, whilst the DSPs will satisfy the distribution network. With both the IISO and the DSPs licensed to provide balancing actions, clear routes of coordination between these two entities are required. These are detailed in Section 4.7.

\subsubsection{Module 5: The IISO Ancillary Market}

The IISO would be responsible for national issues on the grid, such as overall grid frequency alongside responding to issues on the transmission networks such as constraints. The products procured and their entry requirements will be standardised to reflect the DSP ancillary markets to aid in the facilitation of market participants from the distribution network into this IISO market.

\subsubsection{Module 6: The IISO Balancing Market}

With balancing actions performed by both DSPs and the IISO, there is need to coordinate the actions taken by each institution. This design proposes a two-step gate closure to facilitate this. Once the DSP has attempted to balance their geographical region, their final physical notification (FPN) is provided to the IISO $5 \mathrm{~min}$ before real time. At this time, all transmission-connected generation/demand active within this particular settlement period would have also provided their FPN to the IISO. The IISO will then have an overview of the entire distribution and transmission network, allowing them to determine the balancing action required. This process is illustrated in Figure 2.

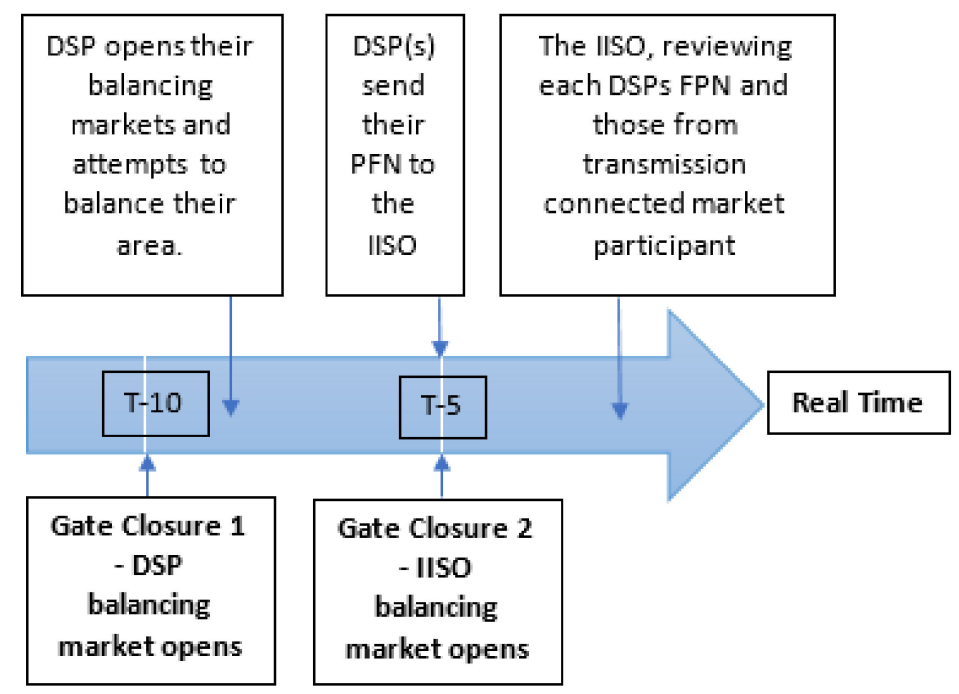

Figure 2. Proposed timeline of events illustrating the two-gate closure process. Authors' own.

By providing an overview of the entire network to the IISO, it may indicate how the culmination of imbalances from DSP regions, and deviations from the contracted positions of transmission-connected market participants may in fact 'net off', reducing the need for balancing actions. This knowledge would not be known by individual DSPs, justifying the IISO receiving all FPN and implementing any remaining balancing actions. 


\subsection{Coordination}

These six modules are interrelated, and the actions taken within one module could potentially impact upon another. Therefore, effective coordination between the governing institutions - the DSPs, the IISO and the wholesale market manager-is required to mitigate conflicting actions being taken $[11,39]$.

In relation to market participants from within a GSP entering into one of the national markets (Modules 4-6), they would notify their respective DSP of the forecasted trade. This would allow the DSP to identify any network issues which may arise such as power flow, congestion and voltage deviations, and allow for the cancelation of the forecasted trade.

Furthermore, utilising distributed technologies to solve location-specific network issues will require efficient coordination between the IISO and the respective DSP to ensure cost-effective, safe and reliable use of these services $[7,11,20,45,76]$. There are many proposed models for how resolving network-specific issues would function in reality $[11,130]$. Gerald et al. [11] proposes five coordination schemes to facilitate ancillary services between system operators. The DSP ancillary market is based upon the 'local AS market model', with the DSP procuring ancillary services to satisfy their own network before offering any un-used bids to the IISO [11].

\subsection{Exclusion of the Capacity Market}

As explained in Section 2.2.1, the issues stemming from the capacity market have led to this market module being excluded from the proposed design.

However, in an electricity system underpinned by variable generation many argue for a market mechanism to procure reliability [136-138]. Therefore, this paper recommends the exclusion of the capacity market with an introduction of a reliability option scheme instead.

Reliability options provide an alternative mechanism for those with capacity, be that generation or demand, to receive financial payment for the obligation to deliver capacity upon being activated by a predetermined signal $[50,139,140]$. A capacity or demand response provider could offer their capacity via a call option in return for an upfront fee to those requiring security of supply, i.e., an energy supplier. In this example, the energy supplier would be the holder of the call option which provides them the right, but not the obligation, to procure the contracted service at a prespecified strike price. Within the proposed design, this could be the clearing price of the DSP pay-as-clear pool market, the wholesale market or a third party operated market such as a LEM. Upon the strike price stated in the call option being exceeded, the holder of the option is entitled to the difference between their strike price and the strike price [139,140].

This insures the option holder against high market clearing prices, whereas the counterparty providing the capacity or demand response secures an upfront fee for their service. This allows risk to be shared between the two parties. The length of the contract can be determined between counterparties, with the scope for longer-term arrangements to aid in the financing of new capacity $[139,140]$. There may also be new business models stemming from opportunities for third parties such as aggregators who can pool multiple smaller capacity providers to meet the requirements of a counterparty.

\subsection{Justification Table}

Table 5, located post conclusion, reviews each of the issues identified in Table 1 and how the proposed reconfigurations can aid in mitigating these. 
Table 5. How the proposed design can aid in mitigating the issues identified within Table 1. Authors' own.

\section{Issue}

Change to Module(s)

Coordinated markets

Nodal (regional investment signals)

Missing money

Nodal (constrained markets)

Scarcity events (transparency and the exclusion of the capacity market)

Nodal (regional investment signals)

Price cannibalisation
Explanation for How This Will Aid in Mitigating the Issues Identified Within Table 1

The introduction of new routes to market(s) can provide additional revenue streams for technologies and services which may otherwise find themselves out of merit.

The clearing price at each GSP nodes shall indicate to investors the potential value streams from the deployment of a technology, or the provision of a service, in one GSP opposed to another $[12,13,126]$. Furthermore, in reviewing trends over time within the various marketplaces, it may provide investors with insights as to when particular DSP

pay-as-clear pool markets may be at risk of being oversupplied, which could result in specific technologies being out of merit. With this information, they can avoid the deployment of a technology or the provision of a service in this marketplace, in favour of another.

The nodal structure represents multiple constrained markets as opposed to the current signal bidding zone in GB. Therefore, a generating or demand-side asset within one GSP will not be competing directly against a GSP in another part of the country. As such, a market participant would be directly competing against those located within their GSP

which may lessen the depression of the market clearing price depending upon the proportion of VRE generation and required load to satisfy.

The formation of power prices at the local level will reflect regional scarcity and thus the market clearing price will allow for transparent scarcity events to emerge [20,73], a solution suggested by [60] to overcome the missing money phenomenon. Furthermore, the capacity market has been excluded to reduce the dampening effects of this out-of-market mechanism on the emergence of scarcity prices [67].

Similar to missing money. Transparent clearing prices of the bids being accepted/rejected will provide investors with the data to identify whether a GSP region is close to cannibalising prices at times of high VRE output.

The flexibility markets of both Modules 1 and 4 will provide an established route for the procurement of flexible technologies. These technologies, when coupled with VRE, can prevent cannibalisation events through storing excess generation during peaks [141,142]. 
Table 5. Cont.

Issue

\section{Change to Module(s)}

Specific markets for flexibility

Lacking flexibility
Explanation for How This Will Aid in Mitigating the Issues Identified Within Table 1

The flexibility markets of both Modules 1 and 4 will provide a clear reference price for flexible actions within each market module.

Allowing flexible load from across the energy system to provide flexibility will unlock large flexible capacity which could be cheaper than sourcing flexibility from the electricity silo $[43,44,101]$.

Transparent trade data for bilateral trades alongside the pool market structures shall aid in revealing the value of specific services.

Trade data are made transparent to aid in revealing the value of specific services. This may reveal the value for specific services at different nodes on the network.

By excluding transmission-connected technologies from directly competing in the DSP local balancing and coordinating market (Modules 1-3), only technologies within that geographical area will be represented in the clearing and bid/offer prices of these markets.
Not reflecting regional differences

Nodal (geographically constrained)
Nodal (transparency of prices) 


\section{Conclusions}

The electricity market design highly influences the transition pathway of the electricity sector through the determination of the technologies, and services, which can access value by defining the products to be procured and the entry requirements to these marketplaces. The move from a predominantly centralised electricity sector to one which values distributed technologies and services provides opportunities for new modes of operation and innovative business models and can aid in the facilitation of net zero. However, design of the electricity market has to enable the monetary capture of this value for distributed market participants to provide an investment case for their deployment.

The efficacy of GB's electricity market design is diminishing as a result of the shift towards an increasingly variable and decentralised electricity sector. This article has demonstrated how the current electricity economics are skewed towards centralised forms of technologies, coined the distribution gap. The consequence of excluding DER are twofold. First, DER owners are unable to receive the monetary value for the services they can provide, they face a higher hurdle rate, constraining future investment and ultimately slowing the shift to a net zero electricity system. Second, as centralised technologies do receive financial compensation for their services, this aids in the lock in of these often carbon-intensive generating assets technologies whilst locking out DER.

In response to the aforementioned issues with GB's current electricity market design and the benefits which can be unlocked through the exploitation of new opportunities, a new electricity market design is proposed. The design, built upon a review of 30 previously proposed electricity market designs and appraised by industry experts, consists of several re-configurations to GB's current design. First, a local balancing and coordinating market is introduced at each GSP. This is achieved through a pay-as-clear pool, balancing and ancillary market at each of the GSP nodes, with relevant trade data made publicly available. The local balancing and coordinating markets provide a route to market for distributed technologies and services provided by the demand side, and in doing so promotes a more efficient use of the network. The transparent nature of these marketplaces can help to reveal the value attributed to specific services and technologies, evidencing the investment case for DER. Second, the existing wholesale market is reconfigured to reflect the GSP market structure to standardise and ease market entrance between the local and national level providing further routes to market for distributed market participants. Table 5 below states how the proposed electricity market design in Section 4 can aid in mitigating the issues identified in Table 1. In proposing a holistic re-configuration to GB's electricity market design, the system governance is also reviewed. First, the evolutions of existing governing institutions are introduced to facilitate the smooth operation and efficient coordination of this market design. Second, in pursuing a SES approach, the design fits into the wider institutional governance by unifying the heat, transport and electricity sectors, and therefore plays a pivotal role in the overall energy sector transformation-an outcome often overlooked when proposing an electricity market design.

Three areas for further research can be identified. First, mathematical modelling of the conceptual framework would aid in the validation of this proposed design and provide insights beyond the qualitative research presented here. Second, while this research has focused on DAH and IDM timescales, further work is needed to consider the impact of a highly variable, increasingly decentralised electricity system on the future market. Finally, the process of electricity market design evolution is an inherently political process with rules enshrined in legislation, codes and regulation. In order to move from the current market design to that of the design proposed here, a greater understanding of the practicalities of this transition is required.

Author Contributions: All authors were responsible for the conceptualisation of the electricity market design, writing, editing and reviewing this paper. All authors have read and agreed to the published version of the manuscript. 
Funding: The author(s) received no financial support for the research, authorship, and/or publication of this article.

Institutional Review Board Statement: Not applicable.

Informed Consent Statement: Informed consent was obtained from all subjects involved in the study.

Data Availability Statement: The paper did not utilise data, and therefore there is no data to access.

Acknowledgments: We would like to acknowledge and thank the multiple interviewees for their time and expertise, without which the conceptualisation of the electricity market design would not be possible. We would also like to thank the two anonymous reviewers for their comments on an earlier version of this paper.

Conflicts of Interest: The authors declare no conflict of interest. The funders had no role in the design of the study; in the collection, analyses, or interpretation of data; in the writing of the manuscript, or in the decision to publish the results.

$\begin{array}{ll}\text { Abbreviations } \\ \text { CfD } & \text { Contract for Difference } \\ \text { DAH } & \text { Day Ahead } \\ \text { DER } & \text { Distributed Energy Resources } \\ \text { DLMP } & \text { Distributed Locational Marginal Price } \\ \text { DNO } & \text { Distribution Network Operator } \\ \text { DSODSP } & \text { Distributed System Operator Distributed Service Provider } \\ \text { DUoS } & \text { Distribution Use of System } \\ \text { EVs } & \text { Electric Vehicles } \\ \text { FES } & \text { Future Energy Scenarios } \\ \text { FPN } & \text { Final Physical Notification } \\ \text { GB } & \text { Great Britain } \\ \text { GSP } & \text { Grid Supply Point } \\ \text { ID } & \text { Intraday } \\ \text { IISO } & \text { Independent Integrated System Operator } \\ \text { IoT } & \text { Internet of Things } \\ \text { LEM } & \text { Local Energy Markets } \\ \text { NETA } & \text { New Electricity Trading Arrangements } \\ \text { ODFM } & \text { Operation Downward Frequency Management } \\ \text { OPEX } & \text { Operational Expenditure } \\ \text { P2P } & \text { Peer to Peer } \\ \text { SES } & \text { Smart Energy System } \\ \text { TNUoS } & \text { Transmission Network Use of System } \\ \text { TSO } & \text { Transmission System Operator } \\ \text { VRE } & \text { Variable Renewable Energy } \\ & \end{array}$

\section{References}

1. Mathews, J.A. The renewable energies technology surge: A new techno-economic paradigm in the making? Futures 2013, 46, 10-22. [CrossRef]

2. BEIS. Electricity Generation Costs. 2020. Available online: https://assets.publishing.service.gov.uk/government/uploads/ system/uploads/attachment_data/file/911817/electricity-generation-cost-report-2020.pdf (accessed on 5 September 2020).

3. Markard, J. The next phase of the energy transition and its implications for research and policy. Nat. Energy 2018, 3, 628-633. [CrossRef]

4. Kern, F.; Kuzemco, C.; Mitchell, C. Measuring and Explaining Policy Paradigm Change. Policy Polit. 2014, 42, 513-530. [CrossRef]

5. HM Government. Powering Our Net Zero Future. Available online: https://assets.publishing.service.gov.uk/government/uploads/ system/uploads/attachment_data/file/943807/201214_BEIS_EWP_Command_Paper_LR.pdf (accessed on 21 December 2020).

6. National Grid ESO. Future Energy Scenarios. Available online: https://www.nationalgrideso.com/future-energy/future-energyscenarios / fes-2020-documents (accessed on 29 July 2020).

7. Papalexopoulos, A.; Frowd, R.; Birbas, A. On the development of organized nodal local energy markets and a framework for the TSO-DSO coordination. Electr. Power Syst. Res. 2020, 189, 106810. [CrossRef]

8. NIC. Smart Power. Available online: https://www.gov.uk/government/uploads/system/uploads/attachment_data/file/5052 18/IC_Energy_Report_web.pdf (accessed on 2 November 2017). 
9. Zhang, C.; Wu, J.; Zhou, Y.; Cheng, M.; Long, C. Peer-to-Peer energy trading in a Microgrid. Appl. Energy 2018, 220 , 1-12. [CrossRef]

10. BEIS, Ofgem. Upgrading Our Energy System, Smart Systems and Flexibility Plan-Call for Evidence Question Summaries and Response from the Government and Ofgem; BEIS, Ofgem: London, UK, 2017.

11. Gerard, H.; Israel, E.; Puente, R.; Six, D. Coordination between transmission and distribution system operators in the electricity sector: A conceptual framework. Util. Policy 2018, 50, 40-48. [CrossRef]

12. Koirala, B.P.; Ávila, J.P.C.; Gómez, T.; Hakvoort, R.A.; Herder, P.M. Local alternative for energy supply: Performance assessment of integrated community energy systems. Energies 2016, 9, 981. [CrossRef]

13. Pérez-Arriaga, I.; Schwenen, S.; Glachant, J. From Distribution Networks to Smart Distribution Systems: Rethinking the Regulation of European Electricity DSOs. Util. Policy 2013. [CrossRef]

14. Energy Networks Association. Active Network Management Good Practice Guide. Available online: http:/ /www.energynetworks. org/modx/assets/files/news/publications/1500205_ENA_ANM_report_AW_online.pdf (accessed on 14 April 2017).

15. Poudineh, R.; Jamasb, T. Distributed generation, storage, demand response and energy efficiency as alternatives to grid capacity enhancement. Energy Policy 2014, 67, 222-231. [CrossRef]

16. Spiliotis, K.; Ramos Gutierrez, A.I.; Belmans, R. Demand flexibility versus physical network expansions in distribution grids. Appl. Energy 2016, 182, 613-624. [CrossRef]

17. Strielkowski, W.; Streimikiene, D.; Fomina, A.; Semenova, E. Internet of Energy (IoE) and High-Renewables Electricity System Market Design. Energies 2019, 12, 4790. [CrossRef]

18. Morstyn, T.; Teytelboym, A.; Mcculloch, M.D.; Member, S. Designing Decentralized Markets for Distribution System Flexibility. IEEE Trans. Power Syst. 2018, 34, 2128-2139. [CrossRef]

19. Policy Exchange. Impact of Locational Pricing in Great Britain. Working Paper. 2020. Available online: https:/ / policyexchange. org.uk/wp-content/uploads / Appendix-1-Aurora-Energy-Research.pdf (accessed on 9 January 2021).

20. Mengelkamp, E.; Gärttner, J.; Rock, K.; Kessler, S.; Orsini, L.; Weinhardt, C. Designing microgrid energy markets. Appl. Energy 2017, 210, 870-880. [CrossRef]

21. Roques, F.; Finon, D. Adapting electricity markets to decarbonisation and security of supply objectives: Toward a hybrid regime? Energy Policy 2017, 105, 584-596. [CrossRef]

22. Willis, R.; Mitchell, C.; Hoggett, R.; Britton, J.; Poulter, H.; Pownall, T.; Lowes, R. Getting Energy Governance Right: Lessons from IGov. Working Paper. Available online: http:/ / projects.exeter.ac.uk/igov/wp-content/uploads/2019/08/IGov-Getting-energygovernance-right-Sept2019.pdf (accessed on 20 September 2020).

23. Lockwood, M.; Mitchell, C.; Hoggett, R. Energy Governance in the United Kingdom. In Handbook of Energy Governance in Europe, 1st ed.; Springer International Publishing: Berlin/Heidelberg, Germany, 2019.

24. Mitchell, C. Electricity markets and their regulatory systems for a sustainable future. In Global Energy Issues, Potentials, Policy Implications; Ekins, P., Bradshaw, M., Eds.; Oxford University Press: Oxford, UK, 2015; Volume 6, pp. 45-66. [CrossRef]

25. Chilvers, J.; Foxon, T.J.; Galloway, S.; Hammond, G.P.; Infield, D.; Leach, M.; Pearson, P.J.G.; Strachan, N.; Strbac, G.; Thomson, M. Realising transition pathways for a more electric, low-carbon energy system in the United Kingdom: Challenges, insights and opportunities. Prock. IMeche Part A J. Power Energy 2017, 231, 1-38. [CrossRef]

26. Ford, R.; Hardy, J. Are we seeing clearly? The need for aligned vision and supporting strategies to deliver net-zero electricity systems. Energy Policy 2020, 147, 111902. [CrossRef]

27. Meadowcroft, J. What about the politics? Sustainable development, transition management, and long term energy transitions. Policy Sci. 2009, 42, 323-340. [CrossRef]

28. Kemp, R.; Rotmans, J.; Loorbach, D. Assessing the Dutch energy transition policy: How does it deal with dilemmas of managing transitions? J. Environ. Policy Plan. 2007, 9, 315-331. [CrossRef]

29. European Commission. Clean Energy for All New Electricity Market Design. A Fair Deal for Consumers. Available online: https:/ / ec.europa.eu/energy/sites/ener/files/documents/technical_memo_marketsconsumers.pdf (accessed on 20 June 2018).

30. Kominers, S.D.; Teytelboym, A.; Crawford, V.P. An invitation to market design. Oxf. Rev. Econ. Policy 2017, 33, 541-571. [CrossRef]

31. Leslie, G.; Stern, D.I.; Shanker, A.; Hogan, M.T. Designing Electricity Markets for High Penetrations of Zero or Low Marginal Cost Intermittent Energy Sources. SSRN Electron. J. 2020. [CrossRef]

32. Judson, E.; Fitch-Roy, O.; Pownall, T.; Bray, R.; Poulter, H.; Soutar, I.; Lowes, R.; Connor, P.; Britton, J.; Woodman, B.; et al. The centre cannot (always) hold: Examining pathways towards energy system de-centralisation. Renew. Sustain. Energy Rev. 2020, 118. [CrossRef]

33. Bray, R.; Woodman, B.; Connor, P. Policy and Regulatory Barriers to Local Energy Markets in Great Britain Working Paper. Available online: http://geography.exeter.ac.uk/media/universityofexeter/schoolofgeography/images/researchgroups/epg/ 09.05.18_Policy_and_Regulatory_Barriers_to_LEMs_in_GB_BRAY._pdf (accessed on 20 September 2018).

34. Hu, J.; Harmsen, R.; Crijns-Graus, W.; Worrell, E.; van den Broek, M. Identifying barriers to large-scale integration of variable renewable electricity into the electricity market: A literature review of market design. Renew. Sustain. Energy Rev. 2018, 81, 2181-2195. [CrossRef]

35. Green, R. Draining the Pool: The reform of electricity trading in England and Wales. Energy Policy 1999, 27, 515-525. [CrossRef]

36. Bower, J. Why Did Electricity Prices Fall in England and Wales: Market Mechanism or Market Structure? Oxford Institute Energy Studies: Oxford, UK, 2002; pp. 1-57. 
37. European Commission. GB Implementation Plan. Available online: https://ec.europa.eu/energy/sites/ener/files/gb_ implementation_plan-final.pdf (accessed on 21 December 2020).

38. Morstyn, T.; Teytelboym, A.; Hepburn, C.; McCulloch, M.D. Integrating P2P Energy Trading with Probabilistic Distribution Locational Marginal Pricing. IEEE Trans. Smart Grid 2020, 11, 3095-3106. [CrossRef]

39. Ruester, S.; Schwenen, S.; Batlle, C.; Pérez-Arriaga, I. From distribution networks to smart distribution systems: Rethinking the regulation of European electricity DSOs. Util. Policy 2014, 31, 229-237. [CrossRef]

40. Lin, J.; Magnago, F. ELECTRICITY MARKETS Theories and Applications; Wiley-IEEE Press: Hoboken, NJ, USA, 2017.

41. EPEX SPOT. Market Integration of Renewables-Mission Accomplished? Available online: https://www.epexspot.com/sites/ default/files/download_center_files/202009_Marketintegrationofrenewables.pdf (accessed on 11 November 2020).

42. Peng, D.; Poudineh, R. Electricity market design under increasing renewable energy penetration: Misalignments observed in the European Union. Util Policy 2019, 61, 100970. [CrossRef]

43. Sorknæs, P.; Lund, H.; Skov, I.R.; Djørup, S.; Skytte, K.; Morthorst, P.E.; Fausto, F. Smart Energy Markets-Future electricity, gas and heating markets. Renew. Sustain. Energy Rev. 2020, 119. [CrossRef]

44. Lund, H.; Østergaard, P.A.; Connolly, D.; Ridjan, I.; Mathiesen, B.V.; Hvelplund, F.; Thellufsen, J.Z.; Sorknæs, P. Energy storage and smart energy systems. Int. J. Sustain. Energy Plan. Manag. 2016, 11, 3-14. [CrossRef]

45. Rodr, J.; Rib, D.; Carlos, Á.; Peñalvo-l, E. Novel Conceptual Architecture for the Next-Generation Electricity Markets to Enhance a Large Penetration of Renewable Energy. Energies 2019, 12, 2605. [CrossRef]

46. Britton, J.; Marques, A.; Pourmirza, Z. Exploring the potential of Heat as a Service in decarbonisation: Evidence needs and research gaps. Energy Sources Part B Econ. Plan. Policy 2021. [CrossRef]

47. Newbery, D.M. Electricity liberalisation in Britain: The quest for a satisfactory wholesale market design. Energy J. 2005, 26, 43-70. [CrossRef]

48. Legislation.gov.uk. The Electricity Act 1989: Part II: Transfers to Successor Companies. Available online: https://www.legislation. gov.uk/ukpga/1989/29/part/II/crossheading/transfers-to-successor-companies (accessed on 22 December 2020).

49. OFFER. Review of Electricity Trading Arrangements Background Paper 1 Electricity Trading Arrangements in England and Wales. Available online: https:/ / www.ofgem.gov.uk/ofgem-publications/79088/review-electricity-trading-arrangements-backgroundengland-and-walespdf (accessed on 5 March 2018).

50. Cornwall Insight. Challenges of Designing Markets to Bring Forward Low Marginal Cost Resources the Net Zero Paradox Working Paper. Available online: https:/ / www.cornwall-insight.com/insight-papers/the-net-zero-paradox-challenges-ofdesigning-markets-to-bring-forward-low-marginal-cost-resources (accessed on 17 November 2020).

51. Nelson, T.; Orton, F.; Chappel, T. Electricity market design in a decarbonised energy system Electricity market design. Decarbonised Energy Syst. 2017. [CrossRef]

52. De Vries, L.J.; Verzijlbergh, R.A. How renewable energy is reshaping Europe's Electricity market design. Econ. Energy Environ. Policy 2018, 7, 31-49. [CrossRef]

53. COAG Energy Council. Response to Post 2025 Market Design Consultation Paper. Available online: http://www. coagenergycouncil.gov.au/publications/post-2025-market-design-consultation-paper----september-2020 (accessed on 2 October 2020).

54. IRENA. Renewable Power Generation Costs in 2019; IRENA: Abu Dhabi, United Arab Emirates, 2020.

55. BEIS. Dukes 2020 Chapter 5: Electricity. Available online: https://assets.publishing.service.gov.uk/government/uploads/ system/uploads/attachment_data/file/904805/DUKES_2020_Chapter_5.pdf (accessed on 12 November 2020).

56. BEIS. Contracts for Difference for Low Carbon Electricity Generation Consultation on Proposed Amendments to the Scheme. Available online: https://assets.publishing.service.gov.uk/government/uploads/system/uploads/attachment_data/file/88 5248/cfd-ar4-proposed-amendments-consultation.pdf (accessed on 27 November 2020).

57. Keay, M.; Robinson, D. The Decarbonised Electricity System of the Future: The "Two Market" Approach Part 1 Overall Concept Working Paper. Available online: https://www.oxfordenergy.org/wpcms/wp-content/uploads/2017/06/The-DecarbonisedElectricity-Sysytem-of-the-Future-The-Two-Market-Approach-OIES-Energy-Insight.pdf (accessed on 2 June 2018).

58. Riesz, J.; Milligan, M. Designing electricity markets for a high penetration of variable renewables. Energy Environ. 2015, 4. [CrossRef]

59. Bauknecht, D.; Brunekreeft, G.; Meyer, R. From Niche to Mainstream: The Evolution of Renewable Energy in the German Electricity Market. In Evolution of Global Electricity Markets; Elsevier: Amsterdam, The Netherlands, 2013. [CrossRef]

60. Hogan, W.W. On an “Energy Only" Electricity Market Design for Resource Adequacy. Available online: http:// citeseerx.ist.psu. edu/viewdoc/download?doi=10.1.1.438.4422\&rep=rep1\&type=pdf (accessed on 3 May 2018).

61. Cornwall Insight. Wholesale Power Price Cannibalisation. Available online: https://www.cornwall-insight.com/insight-papers/ wholesale-power-price-cannibalisation (accessed on 4 March 2019).

62. López, P.J.; Steininger, K.W.; Zilberman, D. The cannibalization effect of wind and solar in the California wholesale electricity market. Energy Econ. 2020, 85, 104552. [CrossRef]

63. Simshauser, P. On the stability of energy-only markets with government-initiated contracts-for-differences. Energies 2019, 12, 2566. [CrossRef]

64. Green Alliance. Smart Investment. Valuing Flexibility in the UK Electricity Market Working Paper. Available online: https:/ / www.gov.uk/government/uploads/system/uploads/attachment_data/file/568982/An_analysis_of_electricity_ flexibility_for_Great_Britain.pdf (accessed on 5 September 2018). 
65. Shakoor, A.; Davies, G.; Strbac, G. Roadmap for Flexibility Services to 2030. Available online: http:/ / poyry.co.uk/sites/www. poyry.co.uk/files/decentralisedreliabilityoptionspublicreport_v300_0.pdf (accessed on 16 March 2018).

66. Energy UK. Contracts for Difference (CfD). Proposed Amendments to the Scheme 2020. Available online: https://www.gov.uk/ government/consultations/ contracts-for-difference-cfd-proposed-amendments-to-the-scheme-2020 (accessed on 25 September 2020).

67. Energy Systems Catapult. Towards a New Framework for Electricity Markets Working Paper. Available online: https://es. catapult.org.uk/reports/towards-a-new-framework-for-electricity-markets/ (accessed on 12 January 2020).

68. Ofgem. Wholesale Energy Markets in 2016. Available online: https://www.ofgem.gov.uk/system/files/docs/2016/08/ wholesale_energy_markets_in_2016.pdf (accessed on 16 September 2017).

69. Elexon. Where Can I Find Details of Wholesale Prices of Electricity in Great Britain? Available online: https://www.elexon.co.uk/ knowledgebase/where-can-i-find-details-of-wholesale-prices-of-electricity-in-great-britain/ (accessed on 20 November 2020).

70. Ofgem. Decision to Suspend the Secure and Promote Market Making Obligation with Effect. Available online: https://www. ofgem.gov.uk/system/files/docs/2019/11/mmo_suspension_decision_letter_2.pdf (accessed on 13 January 2020).

71. Cramton, P. Electricity market design. Oxford Rev. Econ. Policy 2017, 33, 589-612. [CrossRef]

72. OFGEM. Options for Improving Locational Accuracy of Distribution Charges-Discussion Note. Available online: https://www. ofgem.gov.uk/system/files/docs/2019/09/000_-_working_paper_-_summer_2019_-_locational_charges_note_final.pdf (accessed on 2 August 2020).

73. Nieße, A.; Lehnhoff, S.; Tröschel, M.; Uslar, M.; Wissing, C.; Appelrath, H.J.; Sonnenschein, M. Market-Based Self-Organized Provision of Active Power and Ancillary Services: An Agent-Based Approach for Smart Distribution Grids. In Proceedings of the 2012 IEEE Work Complex Eng COMPENG, Aachen, Germany, 11-13 June 2012; pp. 47-51. [CrossRef]

74. Ofgem. Electricity System Flexibility. Available online: https://www.ofgem.gov.uk/electricity/retail-market/market-reviewand-reform/electricity-system-flexibility (accessed on 26 June 2018).

75. HM Government, Ofgem. Smart Systems and Flexibility Plan Upgrading Our Energy System Smart Systems and Flexibility Plan. Available online: https://www.ofgem.gov.uk/system/files/docs/2017/07/upgrading_our_energy_system_-_smart_systems_ and_flexibility_plan.pdf (accessed on 1 June 2018).

76. Olivella-Rosell, P.; Lloret-Gallego, P.; Munné-Collado, Í.; Villafafila-Robles, R.; Sumper, A.; Ottessen, S.Ø.; Rajasekharan, J.; Bremdal, B.A. Local flexibility market design for aggregators providing multiple flexibility services at distribution network level. Energies 2018, 11, 822. [CrossRef]

77. Sanders, D.; Hart, A.; Ravishankar, M.; Brunert, J. An Analysis of Electricity System Flexibility for Great Britain. Available online: https://www.gov.uk/government/uploads/system/uploads/attachment_data/file/568982/An_analysis_of_electricity_ flexibility_for_Great_Britain.pdf (accessed on 12 September 2017).

78. Stanley, R.; Johnston, J.; Sioshansi, F. Chapter 6: Platforms to Support Non wire Alternatives and DSO Flexibility Trading. In Consumers, Prosumers, Prosumagers: How Service Innovations Will Disrupt the Utility Business Model, 1st ed.; Academic Press: London, UK, 2019; pp. 111-127.

79. Brinkel, N.B.G.; Schram, W.L.; AlSkaif, T.A.; Lampropoulos, I.; van Sark, W.G.J.H.M. Should we reinforce the grid? Cost and emission optimization of electric vehicle charging under different transformer limits. Appl. Energy 2020, 276, 115285. [CrossRef]

80. European Commission. METIS Studies Study S14-Wholesale Market Prices, Revenues and Risks for Producers with High Shares of Variable RES in the Power System; European Commission: Brussels, Belgium, 2018.

81. WPD. Comparison of Price Incentive Models for Locally Matched Electricity Networks. Appendix A: Study on Local Matching. Available online: https:/ /www.westernpower.co.uk/downloads/1907 (accessed on 15 March 2018).

82. National Grid ESO. Potential Transmission Charging Arrangements at Exporting Grid Supply Points (GSPs). Available online: https://www.nationalgrid.com/sites/default/files/documents/42344-ExportingGSPconsultationfinal.pdf (accessed on 13 June 2019).

83. Edomah, N.; Ndulue, G. Energy transition in a lockdown: An analysis of the impact of COVID-19 on changes in electricity demand in Lagos Nigeria. Glob. Transit. 2020, 2, 127-137. [CrossRef] [PubMed]

84. Norouzi, N.; Zarazua de Rubens, G.; Choubanpishehzafar, S.; Enevoldsen, P. When pandemics impact economies and climate change: Exploring the impacts of COVID-19 on oil and electricity demand in China. Energy Res. Soc. Sci. 2020, 68, 101654. [CrossRef] [PubMed]

85. Bahmanyar, A.; Estebsari, A.; Ernst, D. The impact of different COVID-19 containment measures on electricity consumption in Europe. Energy Res. Soc. Sci. 2020, 68, 101683. [CrossRef]

86. National Grid ESO. GC143: Last Resort Disconnection of Embedded Generation. Available online: https: / / www.nationalgrideso. com/document/168336/download (accessed on 11 October 2020).

87. IEA. Covid-19 Impact on Electricity. Available online: https:/ /www.iea.org/reports/covid-19-impact-on-electricity (accessed on 17 November 2020).

88. Zhang, X.; Pellegrino, F.; Shen, J.; Copertaro, B.; Huang, P.; Kumar Saini, P.; Lovati, M. A preliminary simulation study about the impact of COVID-19 crisis on energy demand of a building mix at a district in Sweden. Appl. Energy 2020, 280, 115954. [CrossRef]

89. National Grid ESO. 2019-20 End of Year Report Evidence Chapters. Available online: https://www.nationalgrideso.com/ document/168786/download (accessed on 12 May 2020).

90. Drax. Electric Insights Quarterly (Q2 2020). Available online: https://www.drax.com/wp-content/uploads/2020/08/200828 _Drax20_Q2_Report_005.pdf (accessed on 19 September 2020). 
91. Robinson, D.; Keay, M. Glimpses of the Future Electricity System? Demand Flexibility and a Proposal for a Special Auction. Available online: https://www.oxfordenergy.org/wpcms/wp-content/uploads/2020/10/Glimpses-of-the-future-electricitysystem.pdf (accessed on 27 October 2020).

92. National Grid ESO. CMP 345 `Defer the additional Covid BSUoS Costs'. Available online: https://www.nationalgrideso.com/ document/170686/download (accessed on 14 July 2020).

93. National Grid ESO. GC0147: Mod Title: Last Resort Generation-Enduring Solution. Available online: https://www. nationalgrideso.com/document/173401/download (accessed on 23 September 2020).

94. National Grid ESO. Summer Insights: Webinar 9: ODFM and Managing Low Demand. Available online: http:/ / powerresponsive. com/summer-insights-2020-industry-podcasts/ (accessed on 22 September 2020).

95. National Grid ESO. Grid Code Development Forum. Available online: https://www.nationalgrideso.com/industry-information/ codes/grid-code-old/meetings/grid-code-development-forum-8-july-2020 (accessed on 10 July 2020).

96. Unruh, G.C. Understanding carbon lock-in. Energy Policy 2000, 28, 817-830. [CrossRef]

97. Fligstein, N.; Calder, R. Architecture of Markets. Emerg. Trends Soc. Behav. Sci. 2015, 1-14. [CrossRef]

98. Electric Nation Project. Summary of the Findings of the Electric Nation Smart Charging Trial. Available online: http://www. electricnation.org.uk/2019/07/17/electric-nation-smart-charged-conference-review/ (accessed on 12 January 2020).

99. Oxford City Council. Oxfordshire to trial £40m industry first local energy system project. Available online: https:// www.oxford. gov.uk/news/article/1050/oxfordshire_to_trial_40m_industry_first_local_energy_system_project (accessed on 12 January 2020).

100. BEIS, OLEV. Innovation in Vehicle-To-Grid (V2G) Systems: Real-World Demonstrators. Available online: https://assets. publishing.service.gov.uk/government/uploads/system/uploads/attachment_data/file/681321/Innovation_in_Vehicle-ToGrid_V2G_Systems_-_Real-World_Demonstrators_-_Competition_Results.pdf (accessed on 12 January 2020).

101. Lowes, R.; Rosenow, J.; Qadrdan, M.; Wu, J. Hot stuff: Research and policy principles for heat decarbonisation through smart electrification. Energy Res. Soc. Sci. 2020, 70, 101735. [CrossRef] [PubMed]

102. ESO NG. Wider Access to the GB Balancing Mechanism and TERRE Review and Update. Available online: https://www. nationalgrideso.com/document/170896/download (accessed on 2 August 2020).

103. Flexitricity. Ev.Energy and Flexitricity Partnership Helps Suppliers Unlock Balancing Mechanism with Smart EV Charging. Available online: https:/ / www.flexitricity.com/resources/press-release/evenergy-and-flexitricity-partnership-helps-suppliersunlock-balancing-mechanism-smart-ev-charging/ (accessed on 7 February 2021).

104. BEIS. Capacity Market-Consultation on Future Improvements. 2020. Available online: https:/ /assets.publishing.service.gov.uk/ government/uploads/system/uploads/attachment_data/file/862674/capacity-market-consultation-future-improvements. pdf (accessed on 20 January 2021).

105. Behl, D.V.; Ferreira, S. Systems thinking: An analysis of key factors and relationships. Procedia Comput. Sci. 2014, 36, 104-109. [CrossRef]

106. Arnold, R.D.; Wade, J.P. A Definition of Systems Thinking: A Systems Approach. Procedia Comput. Sci. 2015, 44, 669-678. [CrossRef]

107. Davidz, H.; Nightingale, D. Model Based Systems Engineering with Department of Defense Architectural Framework. Syst. Eng. 2007, 11. [CrossRef]

108. Gharajedaghi, J. Systems Thinking: Managing Chaos and Complexity: A Platform for Designing Business Architecture, 2nd ed.; Elsevier: Burlington, VT, USA, 2011.

109. Esmat, A.; Usaola, J.; Moreno, M.Á. Distribution-level flexibility market for congestion management. Energies 2018, 11, 1056. [CrossRef]

110. Baldwin, C.; Clark, K. Design Rules: The Power of Modularity; The MIT Press: Cambridge, UK, 2000.

111. Alexander, C. A City Is Not a Tree; Sustasis Press: Portland, OR, USA, 2015; ISBN 978-0-9893469-7-9.

112. Franco, C.J.; Castaneda, M.; Dyner, I. Simulating the new British Electricity-Market Reform. Eur. J. Oper. Res. 2015. [CrossRef]

113. Sovacool, B.K. Energy policymaking in Denmark: Implications for global energy security and sustainability. Energy Policy 2013, 61, 829-839. [CrossRef]

114. Lockwood, M. The Danish System of Electricity Policy-Making and Regulation Working Paper. Available online: http:/ / projects. exeter.ac.uk/igov/wp-content/uploads/2015/06/ML-Danish-model-of-regulation.pdf (accessed on 8 December 2017).

115. Policy Exchange. Powering Net Zero. Working Paper. Available online: https://policyexchange.org.uk/wp-content/uploads/ Electricity-Market-Design.pdf (accessed on 8 January 2021).

116. Bryman, A. Social Research Methods, 5th ed.; Oxford University Press: Oxford, UK, 2016.

117. National Grid ESO. Final Report Second Balancing Services Charges Task Force. Available online: http:/ / chargingfutures.com/ media/1477/second-balancing-services-charges-task-force-final-report.pdf (accessed on 17 September 2020).

118. Market4Res. Post-2020 Framework for a Liberalised Electricity Market with a Large share of Renewable Energy Sources. Available online: https: / / market4res.eu/wp-content/uploads/LR-Market4RES-final-publication.pdf (accessed on 13 June 2017).

119. Ofgem. Great Britain and Northern Ireland Regulatory Authorities Reports 2017. Available online: https://www.ofgem.gov.uk/ system/files/docs/2017/08/new_donagh_report.pdf (accessed on 2 August 2018).

120. CMA. Appendix 5.2: Locational Pricing in the Electricity Market in Great Britain Contents. Available online: https://assets.publishing. service.gov.uk/media/576bcac940f0b652dd0000a8/appendix-5-2-locational-pricing-fr.pdf (accessed on 18 September 2018).

121. European Commission. The Future Electricity Intraday Market Design. Available online: https://op.europa.eu/en/publicationdetail/-/publication/f85fbc70-4f81-11e9-a8ed-01aa75ed71a1/language-en (accessed on 5 May 2020).

122. EPEXSPOT. Basics of the Power Market. Available online: https://www.epexspot.com/en/basicspowermarket\#powerexchanges-organise-trading-and-operate-markets (accessed on 8 December 2020). 
123. Liu, Z.; Wu, Q.; Oren, S.S.; Huang, S.; Li, R.; Cheng, L. Distribution locational marginal pricing for optimal electric vehicle charging through chance constrained mixed-integer programming. IEEE Trans. Smart Grid 2018, 9, 644-654. [CrossRef]

124. Xu, R.; Liu, Z.; Yu, Z. Exploring the profitability and efficiency of variable renewable energy in spot electricity market: Uncovering the locational price disadvantages. Energies 2019, 12, 2820. [CrossRef]

125. Kristov, L.; De Martini, P.; Taft, J.D. A Tale of Two Visions: Designing a Decentralized Transactive Electric System. IEEE Power Energy Mag. 2016, 14, 63-69. [CrossRef]

126. Mihaylov, M.; Jurado, S.; Avellana, N.; Van Moffaert, K.; De Abril, I.M.; Nowé, A. NRGcoin: Virtual currency for trading of renewable energy in smart grids. Int. Conf. Eur. Energy Mark. EEM 2014. [CrossRef]

127. PicloFlex. Competition Data. Available online: https://docs.google.com/forms/d/e/1FAIpQLSc-1DxZicbDkZy8 WAyjdiLwuvSDefnjrmfB5AjMLq2uVsE_OA/viewform (accessed on 18 December 2020).

128. Xu, Y.; Ahokangas, P.; Louis, J.N.; Pongrácz, E. Electricity market empowered by artificial intelligence: A platform approach. Energies 2019, 12, 4128. [CrossRef]

129. Yuan, Z.; Hesamzadeh, M.R. Hierarchical coordination of TSO-DSO economic dispatch considering large-scale integration of distributed energy resources. Appl. Energy 2017, 195, 600-615. [CrossRef]

130. ENTSOE. TSO-DSO Report an Integrated Approach to Active System Management with the Focus on TSO-DSO Coordination in Congestion Management and Balancing Content. Available online: https: / / eepublicdownloads.azureedge.net/clean-documents / Publications / Positionpapersandreports/TSO-DSO_ASM_2019_190416.pdf (accessed on 12 May 2020).

131. National Grid ESO. The Power Potential Project A Guide to Participating. Available online: https://www.nationalgrid.com/ sites/default/ files/documents / PowerPotentialguidetoparticipating_0.pdf (accessed on 5 June 2018).

132. National Grid ESO. Dynamic Containment 2. Available online: https://www.nationalgrideso.com/document/162381/download (accessed on 3 February 2020).

133. National Grid ESO. Frequently Asked Questions: The Power Potential Project V2 December. Available online: https://www. nationalgrideso.com/innovation/projects/power-potential (accessed on 4 March 2020).

134. Energy Networks Association. Open Networks Project: Opening Markets for Network Flexibility. Available online: http://www. energynetworks.org/assets / files / electricity / futures /Open_Networks/14574_ENA_OpenNetworksReport_AW_v9_Web.pdf (accessed on 17 June 2020).

135. Willis, R.; Mitchell, C.; Hoggett, R. Enabling the Transformation of the Energy System: Recommendations from IGov. Available online: http:/ / projects.exeter.ac.uk/igov/wp-content/uploads/2019/04/IGov-Enabling-the-transformation-of-the-energysystem-Sept2019.pdf (accessed on 12 September 2019).

136. BEIS. Electricity Market Reform: Capacity Market-GOV.UK. Available online: https://www.gov.uk/government/collections / electricity-market-reform-capacity-market (accessed on 19 August 2017).

137. Lockwood, M. The Development of the Capacity Market for Electricity in Great Britain. Available online: http:/ / projects.exeter. ac.uk/igov/wp-content/uploads/2017/10/WP-1702-Capacity-Market.pdf (accessed on 23 May 2019).

138. Milstein, I.; Tishler, A. On the effects of capacity payments in competitive electricity markets: Capacity adequacy, price cap, and reliability. Energy Policy 2019, 129, 370-385. [CrossRef]

139. Energy Systems Catapult. Broad Model for a Capacity Remuneration Mechanism in an ESP-led market. Available online: https://es.catapult.org.uk/reports/broad-model-for-a-capacity-remuneration-mechanism/ (accessed on 12 March 2020).

140. Pöyry. Decentralised Reliability Options-Securing Energy Markets. Available online: http://poyry.co.uk/sites/www.poyry.co. uk/files/decentralisedreliabilityoptionspublicreport_v300_0.pdf (accessed on 12 March 2020).

141. IRENA. Electricity Storage Valuation Framework: Assessing System Value and Ensuring Project Viability. Available online: https:/ / www.irena.org/publications/2020/Mar/Electricity-Storage-Valuation-Framework-2020 (accessed on 2 April 2020).

142. Kraan, O.; Kramer, G.J.; Nikolic, I.; Chappin, E.; Koning, V. Why fully liberalised electricity markets will fail to meet deep decarbonisation targets even with strong carbon pricing. Energy Policy 2019, 131, 99-110. [CrossRef] 